\title{
Communication
}

\section{Sleep Duration in Mouse Models of Neurodevelopmental Disorders}

\author{
Rachel Michelle Saré $\mathbb{D}$, Abigail Lemons, Alex Song and Carolyn Beebe Smith *
}

\begin{abstract}
Department of Health and Human Services, National Institutes of Health, National Institute of Mental Health, Section on Neuroadaptation and Protein Metabolism, Bethesda, MD 20814, USA; Rachel.Sare@nih.gov (R.M.S.); abigaillemons7@gmail.com (A.L.); alexsong2014@u.northwestern.edu (A.S.)

* Correspondence: beebe@mail.nih.gov; Tel.: +1-301-402-3120
\end{abstract}

check for

updates

Citation: Saré, R.M.; Lemons, A.;

Song, A.; Smith, C.B. Sleep Duration

in Mouse Models of

Neurodevelopmental Disorders.

Brain Sci. 2021, 11, 31. https://

doi.org/10.3390/brainsci11010031

Received: 25 November 2020

Accepted: 22 December 2020

Published: 30 December 2020

Publisher's Note: MDPI stays neutral with regard to jurisdictional clai$\mathrm{ms}$ in published maps and institutional affiliations.

Copyright: $\odot 2020$ by the authors. Licensee MDPI, Basel, Switzerland. This article is an open access article distributed under the terms and conditions of the Creative Commons Attribution (CC BY) license (https:// creativecommons.org/licenses/by/ $4.0 /)$.
Abstract: Sleep abnormalities are common in patients with neurodevelopmental disorders, and it is thought that deficits in sleep may contribute to the unfolding of symptoms in these disorders. Appreciating sleep abnormalities in neurodevelopmental disorders could be important for designing a treatment for these disorders. We studied sleep duration in three mouse models by means of home-cage monitoring: $\mathrm{Tsc}^{+/-}$(tuberous sclerosis complex), oxytocin receptor (Oxtr) knockout (KO) (autism spectrum disorders), and Shank3 ${ }^{e 4-9} \mathrm{KO}$ (Phelan-McDermid syndrome). We studied both male and female mice, and data were analyzed to examine effects of both genotype and sex. In general, we found that female mice slept less than males regardless of genotype or phase. We did not find any differences in sleep duration in either $T s c 2^{+/-}$or Oxtr $\mathrm{KO}$ mice, compared to controls. In Shank ${ }^{e 4-9} \mathrm{KO}$ mice, we found a statistically significant genotype $\mathrm{x}$ phase interaction $(p=0.002)$ with a trend that Shank $3^{e 4-9} \mathrm{KO}$ mice regardless of sex slept more than control mice in the active phase. Our results have implications for the management of patients with Phelan-McDermid syndrome.

Keywords: neurodevelopmental disorders; sleep duration; Phelan-McDermid syndrome; Shank3; oxytocin receptor; tuberous sclerosis

\section{Introduction}

Sleep abnormalities are prevalent in patients with neurodevelopmental disorders. In particular, $50-85 \%$ of patients with autism spectrum disorders (ASD) are reported to have some sort of sleep disturbance, most commonly reduced total sleep duration [1]. We hypothesized that sleep reduction may play a role in the unfolding of these disorders [1] and determined that it is an important phenotype to investigate. Patient studies of neurodevelopmental disorders can be problematic because many factors can affect sleep, including sleep hygiene, medications, and other environmental influences, and these factors are difficult to control in clinical studies.

Mouse models offer an alternative means to investigate sleep abnormalities in ASD and their molecular underpinnings. Published reports indicate sleep abnormalities in several mouse models of neurodevelopmental disorders, including Angelman syndrome [2], Down syndrome [3], fragile X syndrome [4,5], and Rett syndrome [6]. Several mouse models of ASD have also been reported to have sleep abnormalities, including 16p11.2 deletion [7], BALBC [8], Gabrb3 KO [9], neuroligin-1 KO [10], and neuroligin-3 KO [11] mice.

Tuberous sclerosis complex (TSC) is characterized by a mutation in either the TSC1 or TSC2 genes [12]; approximately 50\% of patients with TSC have ASD [13]. A few reports of patients with TSC suggest the prevalence of sleep abnormalities in 30-90\% of patients [1]. Circadian rhythm abnormalities have been reported in a mouse model of TSC [14], though sleep behavior per se has not been examined. Oxytocin is an important hormone involved in social bonding, and Oxtr $\mathrm{KO}$ mice have been shown to exhibit impaired social interactions and impaired social communication [15]. Sleep behavior has not been examined in this model. Phelan-McDermid syndrome is characterized by deletion of the chromosomal region 22q13, which contains the SHANK3 gene. Point mutations in SHANK3 can cause 
many of the features of Phelan-McDermid syndrome, leading some to believe that it is causally involved in the disorder [16]. In patients with Phelan-McDermid syndrome, 25\% have ASD and $90 \%$ may have sleep problems [17]. A recent study showed that Shank $3^{\Delta C}$ $\mathrm{KO}$ mice had decreased sleep duration in the active phase, difficulty with sleep rebound, and abnormal circadian rhythm [18].

We sought to further characterize sleep in additional mouse models of neurodevelopmental disorders. Here, we used home-cage monitoring to study sleep in $\mathrm{Tsc} 2^{+/-}, \mathrm{Oxtr}$ $\mathrm{KO}$, and Shank $3^{e 4-9} \mathrm{KO}$ mice. We found that sleep duration is not statistically significantly different in either $\mathrm{Tsc}^{+/-}$or Oxtr $\mathrm{KO}$ mice compared to their respective controls. In Shank3 ${ }^{e 4-9} \mathrm{KO}$ mice, we found a statistically significant genotype $\mathrm{x}$ phase interaction indicating genotype-dependent and sex-independent differences in sleep duration in the active phase. Our results have implications for the management of patients with Phelan-McDermid syndrome.

\section{Materials and Methods}

\subsection{Animals}

All animal procedures were conducted in accordance with the National Institutes of Health Guidelines on the Care and Use of Animals and were approved by the National Institute of Mental Health Animal Care and Use Committee (LCM-07). Mice were kept on a standard 12:12 light:dark cycle with lights on at 6:00 AM. Mice had access to food and water ad libitum with standard housing conditions in a central facility. Animals were weaned at 21 days of age. DNA was collected from either tail or ear clippings for genotyping.

\subsection{TSC}

$\mathrm{Tsc}^{+/-}$and WT breeding pairs on a C57BL/6J background were a gift from Mark Bear (MIT, Boston, MA, USA). These animals are commercially available from Jackson Labs (Jackson Labs: B6; 129S4-Tsc2tm1Djk/J Stock No: 004686). Mice were genotyped as described by Jackson Labs (http://www.jax.org/strain/004686). Tsc2 ${ }^{+/-}$mice and WT littermates were studied.

\subsection{Oxtr KO}

$\mathrm{Oxtr}^{+/-}$breeding pairs on a C57BL/6J background were a gift from Scott Young (NIMH, Bethesda, MD, USA) and were genotyped as previously described [19]. Oxtr KO, $\mathrm{Oxtr}^{+-}$, and WT littermates were studied.

\subsection{Shank $3^{e 4-9} \mathrm{KO}$}

Shank3 ${ }^{e 4-9+/-}$ breeding pairs on a C57BL/6J background were purchased from Jackson Labs (Bar Harbor, ME, USA) (B6.129S7-Shank3tm1Yhj/J Stock No: 017442) and were genotyped as described by Jackson Labs (https:/ /www.jax.org/strain/017442). Shank3 ${ }^{\text {e4-9 }}$ $\mathrm{KO}$, and Shank3 ${ }^{e 4-9+/-}$, and WT littermates were studied.

\subsection{Home-Cage Assessment of Sleep Duration}

At 60-77 days of age, we assessed sleep duration by means of the home-cage activity monitoring system (Comprehensive Laboratory Animal Monitoring System (CLAMS)) (Columbus Instruments, Columbus, OH, USA) as previously described [20]. Briefly, mice were singly housed in a standard mouse cage for the duration of the sleep assessment. Each cage was placed in a rectangular arena surrounded by infrared emitters and sensors. Photobeams were placed 0.5 inches apart in both the $\mathrm{x}$ and $\mathrm{y}$ planes to generate activity data on a high-resolution grid. The Oxymax program (Columbus Instruments) was used to detect activity in $10 \mathrm{~s}$ epochs. If no activity was recorded in four consecutive epochs (40 s), the animal was considered asleep. This measure has been previously validated against electroencephalogram-defined sleep in C57BL/6J mice [21]. Sleep was analyzed for 72 consecutive hours. To eliminate the effects of habituation, the first $24 \mathrm{~h}$ were not analyzed [4]. 


\subsection{Statistical Analysis}

All data presented as mean \pm standard error of the mean (SEM) were analyzed by means of repeated measures ANOVA with phase (active, inactive) as a within subject variable and genotype and sex as between subjects variables. ANOVA results are presented in Table 1. When appropriate, Bonferroni corrected post-hoc $t$-tests were performed. $p$-values $\leq 0.05$ were considered statistically significant and are denoted with a "**".

Table 1. Results of repeated measures ANOVA with corresponding F-values and $p$-values.

\begin{tabular}{|c|c|c|c|c|}
\hline Model & Interaction & Main Effect & F(df, Error) Value & $p$-Value \\
\hline \multicolumn{5}{|l|}{$\mathrm{Tsc}^{+/-}$} \\
\hline & Sex $\times$ genotype $\times$ phase & & $\mathrm{F}(1,84)=1.325$ & 0.253 \\
\hline & Sex $\times$ phase & & $\mathrm{F}(1,84)=2.361$ & 0.128 \\
\hline & Genotype $\times$ phase & & $\mathrm{F}(1,84)=1.210$ & 0.274 \\
\hline & Sex $\times$ genotype & & $\mathrm{F}(1,84)=1.921$ & 0.169 \\
\hline & & Sex & $\mathrm{F}(1,84)=49.048$ & $<0.001$ * \\
\hline & & Genotype & $\mathrm{F}(1,84)=0.312$ & 0.578 \\
\hline & & Phase & $\mathrm{F}(1,84)=1806.221$ & $<0.001 *$ \\
\hline \multicolumn{5}{|c|}{ Oxtr KO } \\
\hline & Sex $\times$ genotype $\times$ phase & & $\mathrm{F}(2,126)=1.022$ & 0.363 \\
\hline & Sex $\times$ phase & & $F(1,126)=0.005$ & 0.945 \\
\hline & Genotype $\times$ phase & & $\mathrm{F}(2,126)=0.983$ & 0.377 \\
\hline & Sex $\times$ genotype & & $\mathrm{F}(2,126)=0.396$ & 0.674 \\
\hline & & Sex & $F(1,126)=63.486$ & $<0.001$ * \\
\hline & & Genotype & $\mathrm{F}(2,126)=0.987$ & 0.375 \\
\hline & & Phase & $F(1,126)=2481.879$ & $<0.001$ * \\
\hline \multicolumn{5}{|c|}{$\begin{array}{l}\text { Shank3 e4-9 } \\
\mathrm{KO}\end{array}$} \\
\hline & Sex $\times$ genotype $\times$ phase & & $\mathrm{F}(2,137)=0.537$ & 0.586 \\
\hline & Sex $\times$ phase & & $F(1,137)=0.125$ & 0.725 \\
\hline & Genotype $\times$ phase & & $F(2,137)=6.480$ & $0.002 *$ \\
\hline & Sex $\times$ genotype & & $F(2,137)=0.708$ & 0.494 \\
\hline & & Sex & $F(1,137)=74.197$ & $<0.001$ * \\
\hline & & Genotype & $\mathrm{F}(2,137)=0.230$ & 0.795 \\
\hline & & Phase & $F(1,137)=3771.461$ & $<0.001$ * \\
\hline
\end{tabular}

$p$-values $\leq 0.05$ were considered statistically significant and are denoted with a "*".

\section{Results}

\subsection{Sleep Duration in a Mouse Model of TSC}

We analyzed sleep duration in male and female adult $\mathrm{Tsc}^{+/-}$and control mice (raw data in Supplemental Table S1) and found statistically significant main effects of phase $(p<0.001)$ and sex $(p<0.001)$ but no interactions or main effects of genotype (Table 1$)$. These data show that animals regardless of genotype or sex slept more in the inactive phase (light) than the active phase (dark) (Figure 1). Additionally, regardless of phase or genotype, females slept less than males (Figure 1). 

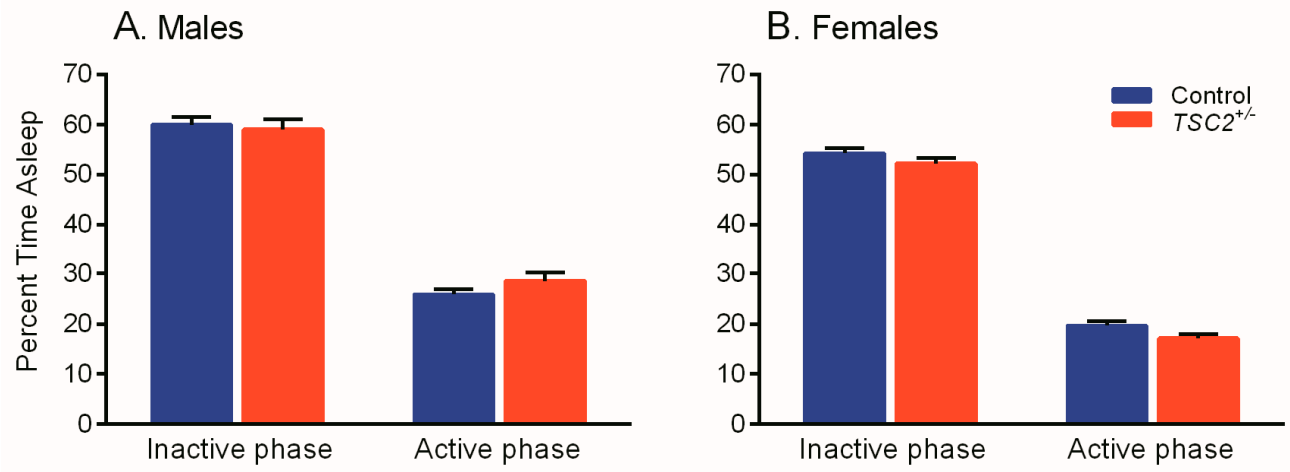

Figure 1. Sleep duration in $T s c 2^{+/-}$and control male (A) and female (B) mice. We found statistically significant main effects of phase and sex, but no statistically significant interaction or main effects of genotype (Table 1). Mice slept less in the active phase than in the inactive phase $(p<0.001)$. Females slept less than male mice $(p<0.001)$. Bars represent means \pm SEM for 22 control male, $22 \mathrm{Tsc}^{+/-}$male, 23 control female, and $21 \mathrm{Tsc} 2^{+/-}$female mice.

\subsection{Sleep Duration in Oxtr KO Mice}

In male and female adult control, heterozygous, and Oxtr $\mathrm{KO}$ mice (raw data in Supplemental Table S2, we found statistically significant main effects of phase $(p<0.001)$ and sex $(p<0.001)$ but no statistically significant interactions or main effects of genotype (Table 1). These data show that animals, regardless of genotype or sex, slept more in the inactive phase than the active phase (Figure 2). Additionally, regardless of phase or genotype, females slept less than males (Figure 2).

A. Males



B. Females



Figure 2. Sleep duration in oxytocin receptor (Oxtr) Oxtr knockout (KO), Oxtr ${ }^{+/-}$, and control male (A) and female (B) mice. We found statistically significant main effects of phase and sex, but no statistically significant interactions or main effects of genotype (Table 1). Mice slept less in the active phase compared to the inactive phase $(p<0.001)$. Females slept less than males $(p<0.001)$. Bars represent means \pm SEM for 23 control male, $21 \mathrm{Oxtr}^{+/-}$male, $22 \mathrm{KO}$ male, 14 control female, $31 \mathrm{Oxtr}^{+/-}$female, and $21 \mathrm{KO}$ female mice.

\subsection{Sleep Duration in Shank ${ }^{\text {e4-9 }}$ Mouse Model of Phelan-McDermid Syndrome}

In male and female adult control, heterozygous, and Shank3 ${ }^{e 4-9} \mathrm{KO}$ mice (raw data in Supplemental Table S3), we found a statistically significant genotype $x$ phase interaction $(p=0.002)$ (Table 1). Regardless of sex, Shank ${ }^{e 4-9} \mathrm{KO}$ mice tended to have increased sleep $(11 \%)$ compared to control mice in the active phase $(p=0.059)$, but sleep duration in the inactive phase was similar for all three genotypes (Figure 3). Main effects of phase $(p<0.001)$ and sex $(p<0.001)$ were also statistically significant (Table 1$)$. These data show that animals regardless of genotype or sex slept more in the inactive phase than the active phase (Figure 3), and regardless of phase or genotype, females slept less than males (Figure 3). 

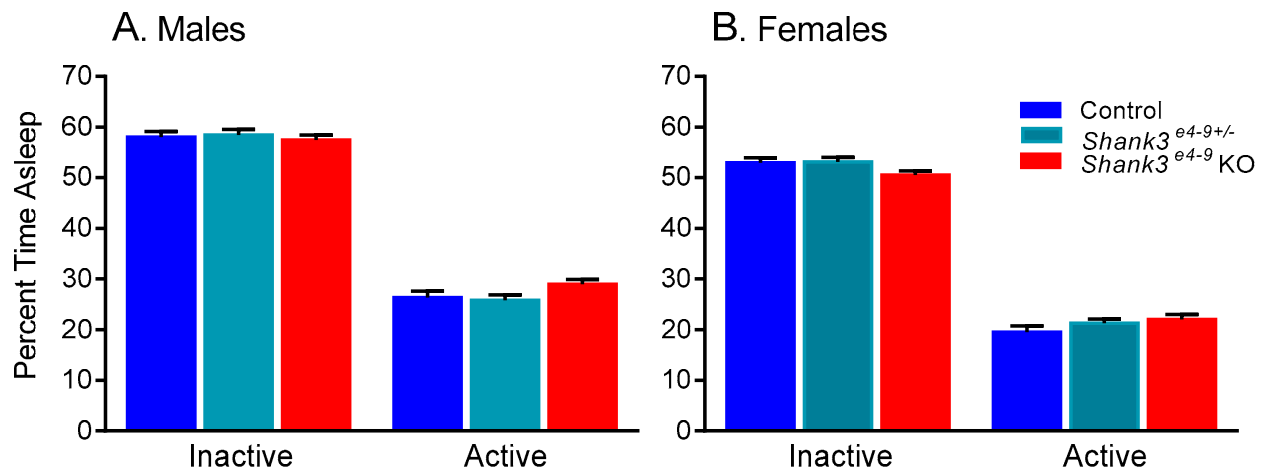

Figure 3. Sleep duration in Shank3 ${ }^{e 4-9} \mathrm{KO}$, Shank3 ${ }^{e 4-9+/-}$, and control male (A) and female (B) mice. We found a statistically significant genotype $\mathrm{x}$ phase $(p=0.002)$ interaction (Table 1$)$. Post-hoc tests showed that KO mice tended to sleep more in that active phase compared to control mice $(p=0.059)$. We also found statistically significant main effects of phase and sex (Table 1). Mice slept less in the active phase than in the inactive phase $(p<0.001)$. Female mice slept less than male mice $(p<0.001)$. Bars represent means \pm SEM for 20 control male, 31 Shank $3^{e 4-9+/-}$ male, 22 KO male, 23 control female, 25 Shank3 ${ }^{e 4-9+/-}$ female, and $22 \mathrm{KO}$ female mice.

\section{Discussion}

Sleep duration in genetic mouse models of TSC, Phelan-McDermid syndrome, and ASD was affected only minimally. In all models, we confirmed a large difference in sleep duration between the active and inactive phases. We also consistently found that there was a large sex difference, such that female mice slept significantly less than male mice. Effects on sleep duration due to genotype were not striking. The only model in which a difference in sleep duration was noted was the Shank $3^{e 4-9} \mathrm{KO}$ model in which we found a significant genotype $x$ phase interaction and a trend toward increased sleep duration in the active phase.

The methodology we used in this study is simple to execute and allows for the study of large groups of animals useful for statistical comparisons. No surgical intervention is required, so confounds due to anesthesia and surgery are avoided. Home-cage monitoring, however, can only measure sleep duration and may miss more subtle changes in sleep patterns such as effects on stages of sleep and sleep spindles. It is hypothesized that rapid eye movemnt sleep abnormalities are prevalent in patients with ASD [22] and that patients with ASD have decreased sleep spindles [23]. Therefore, it may be that subtle sleep abnormalities may still play a role in neurodevelopmental disorders and/or ASD.

Sleep is regulated by two processes: circadian rhythm and sleep homeostasis [24]. Abnormalities in circadian rhythm and associated genes are hypothesized to be involved in ASD [25]. Another possibility is that sleep abnormalities in neurodevelopmental disorders may result from reduced response to sleep homeostatic demands. It may be that sleep in optimal environments is unaltered, but if sleep is disrupted due to, for example, noise, changes in temperature, or a novel environment, patients may be unable to rebound and recover sleep loss. Examining the homeostatic response to sleep loss in mouse models of neurodevelopmental disorders may be a useful indicator of such abnormalities.

We studied mouse models of three neurodevelopmental disorders: TSC, PhelanMcDermid syndrome, and ASD. Although we did not detect significant differences in sleep duration in $\mathrm{Tsc}^{+/-}$mice, circadian rhythm abnormalities have been observed. In constant darkness, $\mathrm{Tsc}^{+/-}$mice had a shorter free-running period than control mice [14]. In Oxtr KO mice, we did not detect differences in sleep duration, but the Oxtr has been implicated in circadian rhythm regulation. Studies in hamsters demonstrate that injection of an Oxtr agonist or antagonist inhibited light-induced phase advances or light-induced phase delays, respectively [26]. Oxytocin likely plays a role in the phase delay experienced by light in the early night. 
Our findings in Shank $3^{e 4-9} \mathrm{KO}$ mice showing a significant genotype $\mathrm{x}$ phase interaction suggest increased sleep in the active phase compared to control mice. Our results contrast with a recent EEG study of Shank $3^{\Delta C} \mathrm{KO}$ mice in which reduced sleep duration in the active phase was reported [18]. The affected isoform of Shank3 differed in our study, suggesting that Shank3 may be involved in the regulation of sleep but in a complex manner. Our results are in agreement with a recent study by Angelakos et al., who reported hypoactivity in the active phase of Shank $3^{e 13-16} \mathrm{KO}$ mice [27]. Interestingly, they also report hypoactivity in the active phase in three other mouse models of neurodevelopmental disorders: Cntnap $2^{-1-}$, Pcdh10 $0^{+-}$, and Fmr1 KO mice [27].

One of our robust findings is that females consistently slept less than male mice regardless of genotype (about 10\% difference in the active phase and $25 \%$ difference in the inactive phase). It is important to note that we did not control for the estrous cycle, and this could be a potential confound of the results. This sex difference in sleep duration has been noted previously in mouse studies [28,29]. In human populations, women are not reported to have reduced sleep duration compared to men; however, they do have increased sleep onset latencies and have a higher incidence of insomnia compared to men [30]. This may contribute to a higher susceptibility to mood disorders and to Alzheimer's disease in females [31,32]. Our studies highlight the importance of separating males and females in studies of sleep.

In summary, reduced sleep duration, as determined by home-cage monitoring, was not seen in any of the three mouse models of neurodevelopmental disorders examined in our study. It could still be that more subtle differences in sleep characteristics may occur in neurodevelopmental disorders, so future studies should address potential differences in REM sleep as well as sleep homeostasis.

Supplementary Materials: The following are available online at https:/ /www.mdpi.com/2076-342 5/11/1/31/s1, Table S1: Raw sleep duration data for $\mathrm{TSC}^{+/-}$mice and controls, Table S2: Raw sleep duration data for Oxtr KO, Oxtr ${ }^{+/}$, and controls, Table S3: Raw sleep duration data for Shank3 ${ }^{\text {e4-9 }}$ $\mathrm{KO}$, Shank $3^{e 4-9} \pm$, and controls.

Author Contributions: R.M.S. conceived and designed the experiments. A.L. and A.S. performed the experiments; R.M.S., A.L., and C.B.S. analyzed the data; and R.M.S. and C.B.S. wrote the paper. All authors have read and agreed to the published version of the manuscript.

Funding: RMS was supported by a postdoctoral fellowship from FRAXA. This work was also supported by the Intramural Research Program of the National Institute of Mental Health (ZIA MH000889).

Institutional Review Board Statement: All animal procedures were conducted in accordance with the National Institutes of Health Guidelines on the Care and Use of Animals and were approved by the National Institute of Mental Health Animal Care and Use Committee (LCM-07).

Informed Consent Statement: Not applicable.

Data Availability Statement: Data is contained in a supplemental file as part of this article.

Acknowledgments: The authors would like to acknowledge Zengyan Xia for mouse colony maintenance. The authors would also like to acknowledge Christine Hildreth for literature research involved in this manuscript.

Conflicts of Interest: The authors declare no conflict of interest. The funders had no role in the design of the study; in the collection, analyses, or interpretation of data; in the writing of the manuscript; or in the decision to publish the results.

\section{References}

1. Picchioni, D.; Reith, R.M.; Nadel, J.L.; Smith, C.B. Sleep, plasticity and the pathophysiology of neurodevelopmental disorders: The potential roles of protein synthesis and other cellular processes. Brain Sci. 2014, 4, 150-201. [CrossRef] [PubMed]

2. Colas, D.; Wagstaff, J.; Fort, P.; Salvert, D.; Sarda, N. Sleep disturbances in Ube3a maternal-deficient mice modeling Angelman syndrome. Neurobiol. Dis. 2005, 20, 471-478. [CrossRef]

3. Colas, D.; Valletta, J.S.; Takimoto-Kimura, R.; Nishino, S.; Fujiki, N.; Mobley, W.C.; Mignot, E. Sleep and EEG features in genetic models of Down syndrome. Neurobiol. Dis. 2008, 30, 1-7. [CrossRef] 
4. Sare, R.M.; Harkless, L.; Levine, M.; Torossian, A.; Sheeler, C.A.; Smith, C.B. Deficient Sleep in Mouse Models of Fragile X Syndrome. Front. Mol. Neurosci. 2017, 10, 280. [CrossRef]

5. Boone, C.E.; Davoudi, H.; Harrold, J.B.; Foster, D.J. Abnormal Sleep Architecture and Hippocampal Circuit Dysfunction in a Mouse Model of Fragile X Syndrome. Neuroscience 2018, 384, 275-289. [CrossRef]

6. Moretti, P.; Bouwknecht, J.A.; Teague, R.; Paylor, R.; Zoghbi, H.Y. Abnormalities of social interactions and home-cage behavior in a mouse model of Rett syndrome. Hum. Mol. Genet. 2005, 14, 205-220. [CrossRef] [PubMed]

7. Horev, G.; Ellegood, J.; Lerch, J.P.; Son, Y.E.; Muthuswamy, L.; Vogel, H.; Krieger, A.M.; Buja, A.; Henkelman, R.M.; Wigler, M.; et al. Dosage-dependent phenotypes in models of 16p11.2 lesions found in autism. Proc. Natl. Acad. Sci. USA 2011, 108, 17076-17081. [CrossRef] [PubMed]

8. Koehl, M.; Battle, S.E.; Turek, F.W. Sleep in female mice: A strain comparison across the estrous cycle. Sleep 2003, 26, 267-272. [CrossRef]

9. Wisor, J.P.; DeLorey, T.M.; Homanics, G.E.; Edgar, D.M. Sleep states and sleep electroencephalographic spectral power in mice lacking the beta 3 subunit of the GABA(A) receptor. Brain Res. 2002, 955, 221-228. [CrossRef]

10. El Helou, J.; Belanger-Nelson, E.; Freyburger, M.; Dorsaz, S.; Curie, T.; La Spada, F.; Gaudreault, P.O.; Beaumont, E.; Pouliot, P.; Lesage, F.; et al. Neuroligin-1 links neuronal activity to sleep-wake regulation. Proc. Natl. Acad. Sci. USA 2013, 110, 9974-9979. [CrossRef]

11. Liu, J.J.; Grace, K.P.; Horner, R.L.; Cortez, M.A.; Shao, Y.; Jia, Z. Neuroligin 3 R451C mutation alters electroencephalography spectral activity in an animal model of autism spectrum disorders. Mol. Brain 2017, 10, 10. [CrossRef]

12. Osborne, J.P.; Fryer, A.; Webb, D. Epidemiology of tuberous sclerosis. Ann. N. Y. Acad. Sci. 1991, 615, 125-127. [CrossRef] [PubMed]

13. Smalley, S.L.; Tanguay, P.E.; Smith, M.; Gutierrez, G. Autism and tuberous sclerosis. J. Autism Dev. Disord. 1992, 22, 339-355. [CrossRef] [PubMed]

14. Lipton, J.O.; Boyle, L.M.; Yuan, E.D.; Hochstrasser, K.J.; Chifamba, F.F.; Nathan, A.; Tsai, P.T.; Davis, F.; Sahin, M. Aberrant Proteostasis of BMAL1 Underlies Circadian Abnormalities in a Paradigmatic mTOR-opathy. Cell Rep. 2017, 20, 868-880. [CrossRef] [PubMed]

15. Pobbe, R.L.; Pearson, B.L.; Defensor, E.B.; Bolivar, V.J.; Young, W.S., 3rd; Lee, H.J.; Blanchard, D.C.; Blanchard, R.J. Oxytocin receptor knockout mice display deficits in the expression of autism-related behaviors. Horm. Behav. 2012, 61, 436-444. [CrossRef] [PubMed]

16. Costales, J.L.; Kolevzon, A. Phelan-McDermid Syndrome and SHANK3: Implications for Treatment. Neurother. J. Am. Soc. Exp. Neurother. 2015, 12, 620-630. [CrossRef]

17. Bro, D.; O’Hara, R.; Primeau, M.; Hanson-Kahn, A.; Hallmayer, J.; Bernstein, J.A. Sleep Disturbances in Individuals With Phelan-McDermid Syndrome: Correlation With Caregivers' Sleep Quality and Daytime Functioning. Sleep 2017, 40. [CrossRef]

18. Ingiosi, A.M.; Schoch, H.; Wintler, T.; Singletary, K.G.; Righelli, D.; Roser, L.G.; Medina, E.; Risso, D.; Frank, M.G.; Peixoto, L. Shank3 modulates sleep and expression of circadian transcription factors. Elife 2019, 8. [CrossRef]

19. Lee, H.J.; Caldwell, H.K.; Macbeth, A.H.; Tolu, S.G.; Young, W.S., 3rd. A conditional knockout mouse line of the oxytocin receptor. Endocrinology 2008, 149, 3256-3263. [CrossRef]

20. Sare, R.M.; Lemons, A.; Torossian, A.; Beebe Smith, C. Noninvasive, High-throughput Determination of Sleep Duration in Rodents. J. Vis. Exp. JoVE 2018. [CrossRef]

21. Pack, A.I.; Galante, R.J.; Maislin, G.; Cater, J.; Metaxas, D.; Lu, S.; Zhang, L.; Von Smith, R.; Kay, T.; Lian, J.; et al. Novel method for high-throughput phenotyping of sleep in mice. Physiol. Genom. 2007, 28, 232-238. [CrossRef]

22. Buckley, A.W.; Rodriguez, A.J.; Jennison, K.; Buckley, J.; Thurm, A.; Sato, S.; Swedo, S. Rapid eye movement sleep percentage in children with autism compared with children with developmental delay and typical development. Arch. Pediatr. Adolesc. Med. 2010, 164, 1032-1037. [CrossRef] [PubMed]

23. Chilakamarri, P.; Thurm, A.; Farmer, C.; Swedo, S.; Burroughs, S.A.; Holmes, G.L.; Buckley, A.W. Characterizing Sleep Spindles in Children with Autism Spectum Disorder (ASD). Neurology 2017, 88, P3.209.

24. Borbely, A.A.; Achermann, P. Sleep homeostasis and models of sleep regulation. J. Biol. Rhythm. 1999, 14, 557-568.

25. Geoffray, M.M.; Nicolas, A.; Speranza, M.; Georgieff, N. Are circadian rhythms new pathways to understand Autism Spectrum Disorder? J. Physiol. Paris 2016, 110, 434-438. [CrossRef]

26. Gannon, R.L. Non-peptide oxytocin receptor ligands and hamster circadian wheel running rhythms. Brain Res. 2014, 1585, 184-190. [CrossRef] [PubMed]

27. Angelakos, C.C.; Tudor, J.C.; Ferri, S.L.; Jongens, T.A.; Abel, T. Home-cage hypoactivity in mouse genetic models of autism spectrum disorder. Neurobiol. Learn. Mem. 2019, 165, 107000. [CrossRef] [PubMed]

28. Paul, K.N.; Dugovic, C.; Turek, F.W.; Laposky, A.D. Diurnal sex differences in the sleep-wake cycle of mice are dependent on gonadal function. Sleep 2006, 29, 1211-1223. [CrossRef]

29. Koehl, M.; Battle, S.; Meerlo, P. Sex differences in sleep: The response to sleep deprivation and restraint stress in mice. Sleep 2006, 29, 1224-1231. [CrossRef]

30. Mallampalli, M.P.; Carter, C.L. Exploring sex and gender differences in sleep health: A Society for Women's Health Research Report. J. Womens Health 2014, 23, 553-562. [CrossRef] 
31. Seney, M.L.; Sibille, E. Sex differences in mood disorders: Perspectives from humans and rodent models. Biol. Sex Differ. 2014, 5, 17. [CrossRef] [PubMed]

32. Vina, J.; Lloret, A. Why women have more Alzheimer's disease than men: Gender and mitochondrial toxicity of amyloid-beta peptide. J. Alzheimers Dis. 2010, 20 (Suppl. 2), S527-S533. [CrossRef] 